Infirmary NHS Trust; Joy Tibbles and Wren Hoskyns, Neonatal Intensive Care Unit, Leicester General Hospital NHS Trust; Helen Holden and Rashmin Tamhne, Directorate of Children's Services, Leicestershire and Rutland Healthcare NHS Trust; Sue Curtis, Nottingham Community Health NHS Trust; R O Walters and Lynne Field, Neonatal Unit, North Hampshire Hospital; P Rowlandson, C Burtwell, and J Turner, Neonatal Unit, St Mary's Hospital NHS Trust, Isle of Wight; C Holme, Royal Devon and Exeter Healthcare NHS Trust; J Barnes and I Webb, Salisbury District Hospital; S Reveley, R Coppen, and S French, Poole Hospital NHS Trust; M A Hall and A Holloway-Moger, Princess Anne Hospital, Southampton; M Sutton, Winchester; and Helen Moody Southampton Community Health. Alistair Shiell provided helped with the random allocation of units.

Funding: NHS Research and Development Programme (Maternal and Child Health). ESD is funded by Leicestershire Health.

Competing interests: None declared.

1 Alberman E, Botting B. Trends in prevalence and survival of very low birthweight infants, England and Wales 1983-7. Arch Dis Child 1991;66:1304-8.

2 House of Commons Health Committee. Session 1991-2. Maternity services: second report. London: HMSO, 1992.
3 Audit Commission. Children first. A study of hospital services. London: HMSO, 1993. (Audit Commission NHS report No 7.)

4 Clinical Standards Advisory Group. Neonatal-intensive care. London: HMSO, 1993

5 Cumberledge J. Changing childbirth. Part 1-report of the expert maternity group. Winterton report. London, HMSO, 1993.

6 National Perinatal Epidemiology Unit and Oxford Regional Health Authority. Disability and perinatal care: measurement of health status at two years. Oxford: National Perinatal Epidemiology Unit, 1994:2-59.

7 Turnbull D. Loss to follow up of preterm and very preterm babies. Lancet 1998:352:1875-6.

8 Johnson A, Townshend P, Yudkin P, Bull D, Wilkinson AR. Functional abilities at age 4 years of children born before 29 weeks of gestation. BMJ 1993;306:1715-8.

9 Blair M. The need for and role of a coordinator in child health surveillance/promotion. Arch Dis Child 2001;84:1-5.

10 Dawson C, Perkins M, Draper E, Johnson A, Field D. Are outcome data regarding the survivors of neonatal care available from routine sources? Arch Dis Child Fetal Neonatal Ed 1997;77:206-10.

11 Wariyor UK, Richmond S. Morbidity and preterm delivery: the importance of $100 \%$ follow-up. Lancet 1989;i:387-8.

12 Hall DMB, ed. Health for all children. Report of the joint working party on child health surveillance. 2nd ed. Oxford: Oxford University Press, 1991.

13 Hall DMB, ed. Health for all children. Report of the third joint working party on child health surveillance. 3rd ed. Oxford: Oxford University Press, 1996.

(Accepted 24 August 2001)

\title{
Implications of childhood obesity for adult health: findings from thousand families cohort study
}

\author{
Charlotte M Wright, Louise Parker, Douglas Lamont, Alan W Craft
}

Donald Court

House, University of

Newcastle upon

Tyne, Gateshead

NE8 1EB

Charlotte M Wright

senior lecturer in

community child

health

Sir James Spence

Institute of Child

Health, University

of Newcastle upon

Tyne, Royal Victoria

Infirmary,

Newcastle NE1 4LP

Louise Parker

reader in

epidemiology

Alan W Craft

James Spence

professor of child

health

24 Seymour Lane,

Alford,

Lincolnshire,

LN13 9AP

Douglas Lamont

senior research

associate

Correspondence to:

C M Wright

C.M.Wright@

Newcastle.ac.uk

BMJ 2001;323:1280-4

\author{
Abstract \\ Objective To determine whether being overweight in \\ childhood increases adult obesity and risk of disease. \\ Design Prospective cohort study. \\ Setting City of Newcastle upon Tyne.
}

Participants 932 members of thousand families 1947 birth cohort, of whom 412 attended for clinical examination age 50 .

Main outcome measures Blood pressure; carotid artery intima-media thickness; fibrinogen concentration; total, low density lipoprotein, and high density lipoprotein cholesterol concentrations; triglyceride concentration; fasting insulin and 2 hour glucose concentrations; body mass index; and percentage body fat.

Results Body mass index at age 9 years was significantly correlated with body mass index age 50 $(r=0.24, \mathrm{P}<0.001)$ but not with percentage body fat age $50(r=0.10, \mathrm{P}=0.07)$. After adult body mass index had been adjusted for, body mass index at age 9 showed a significant inverse association with measures of lipid and glucose metabolism in both sexes and with blood pressure in women. However, after adjustment for adult percentage fat instead of body mass index, only the inverse associations with triglycerides (regression coefficient $=-0.21, \mathrm{P}<0.01$ ) and total cholesterol $(-0.17, \mathrm{P}<0.05)$ in women remained significant

Conclusions Little tracking from childhood overweight to adulthood obesity was found when using a measure of fatness that was independent of build. Only children who were obese at 13 showed an increased risk of obesity as adults. No excess adult health risk from childhood or teenage overweight was found. Being thin in childhood offered no protection against adult fatness, and the thinnest children tended to have the highest adult risk at every level of adult obesity.

\section{Introduction}

Obesity in childhood is reported to be rising dramatically, ${ }^{1}$ and there is concern that this increases the risk of adult morbidity. However, the long term importance of obesity in childhood is not entirely clear. ${ }^{2}$ Some studies have shown that children with weight for height at the top of the normal range are more likely to become obese adults; ${ }^{2}$ others reported an association with higher adult morbidity and mortality. ${ }^{3-10}$ However, these studies could not adjust for adult weight for height, and it is therefore not clear whether this increased risk flows from higher rates of adult obesity or whether childhood obesity itself confers additional risk. The Newcastle thousand families study was a 1947 birth cohort study, first described in $1954 .{ }^{11}$ We used these early data together with information collected on cohort members at the age of 50 to explore the effects of childhood obesity and underweight on adult obesity and risk factors for disease. Our aim was to establish whether being overweight in childhood was associated with any overall increase in adult health risk and, if so, how much of this increased risk could be attributed to a tendency for obese children to become obese adults.

\section{Participants and methods}

The Newcastle thousand families study was a prospective study of the health of all 1142 children recruited at birth during May and June 1947 in the city 
Table 1 Mean (SD) height and body mass index standard deviation scores from childhood to adulthood by father's social class at birth

\begin{tabular}{|c|c|c|c|c|c|c|}
\hline & \multicolumn{3}{|c|}{ Height SD score } & \multicolumn{3}{|c|}{ Body mass index SD score } \\
\hline & Age 9 ( $n=667)$ & Age $13(n=608)$ & Age $50(n=516)$ & Age $9(n=667)$ & Age $13(n=594)$ & Age $50(n=514)$ \\
\hline \multicolumn{7}{|c|}{ Paternal social class at birth: } \\
\hline 1 or 2 & $-0.24(1.03)$ & $-0.99(1.17)$ & $-0.07(0.90)$ & $0.03(0.90)$ & $-0.14(1.11)$ & $0.92(1.14)$ \\
\hline 3 & $-0.39(1.08)$ & $-1.08(1.26)$ & $-0.11(1.04)$ & $-0.04(1.05)$ & $-0.14(1.03)$ & $1.14(1.08)$ \\
\hline 4 & $-0.53(1.11)$ & $-1.24(1.21)$ & $-0.20(0.95)$ & $-0.06(0.95)$ & $-0.08(1.10)$ & $1.30(1.03)$ \\
\hline 5 and unemployed & $-0.84(1.03)$ & $-1.58(1.22)$ & $-0.29(0.97)$ & $0.10(0.92)$ & $-0.10(1.23)$ & $1.40(1.03)$ \\
\hline P value* & $<0.001$ & $<0.001$ & 0.15 & 0.35 & 0.65 & 0.007 \\
\hline
\end{tabular}

${ }^{\star}$ Analysis of variance.

of Newcastle. Two thirds of the cohort were followed until the age of 15 years. ${ }^{12}$ We traced study participants in the 1990s through the UK NHS central register and coded any deaths by cause. Data on fetal development, infancy, and childhood, including birth weight, gestational age, fathers' occupational social class in 1947, and childhood heights and weights, were abstracted from the original study records. We collected data on adult lifestyle, including height, weight, and self reported illness by self completion questionnaire from October 1996 to 1998. Biological risk markers were measured over the same period at a clinical examination, mainly at the Royal Victoria Infirmary, Newcastle, after an overnight fast of at least 10 hours. These comprised ultrasonically measured carotid artery intima-media thickness; blood pressure; plasma fibrinogen concentration; total, low density lipoprotein, and high density lipoprotein cholesterol concentrations; serum triglyceride concentrations; and fasting serum insulin and 2 hour plasma glucose concentrations. Height, weight, and waist circumference were also measured. We used an average of three measurements of bioelectrical impedance (Holtain) to estimate percentage body fat, using standard regression equations.

The analytical procedures used have been described..$^{13}$ The study was approved by the local research ethics committee.

\section{Analysis}

Eleven sets of twins were excluded from all analyses. Heights were available at ages 9 and 13 years for most children. All heights and weights were expressed as standard deviation scores relative to growth standards applicable at that time ${ }^{14}$ to adjust for sex, skew, and variations in age at measurement using the LMS method. ${ }^{15}$ Weight for height was measured by body mass index (weight $(\mathrm{kg}) /\left(\right.$ height $\left.(\mathrm{m})^{2}\right)$ and expressed as a standard deviation score relative to the only available body mass index reference standard. ${ }^{16}$ Adult body mass index was also expressed as standard deviation score, compared to the reference standard at age 20 years, the oldest age for which a reference exists. Two hour plasma glucose, fasting insulin, plasma fibrinogen, serum high density lipoprotein cholesterol, and triglyceride concentrations had skewed distributions and were $\log$ transformed. We identified cases of the metabolic syndrome using criteria for dyslipidaemia, abnormal glucose metabolism, and hypertension described elsewhere. ${ }^{17}$ We assessed the relative contribution of childhood body mass index to adult risk using multiple linear regression with a measure of adult fatness (body mass index or percentage body fat or waist circumference) as covariate.

\section{Results}

Of 1142 children in the original cohort, 932 were followed up to the end of the first year. Forty seven of these participants died after the age of 18 years. At age 50 years, 412 participants (44\%) attended for clinical examination and blood sampling. A total of 688 and 628 participants were measured at age 9 and 13 years, respectively. Heights and weights at age 50 were available for 529 subjects: 409 measured and a further 120 self reported in the postal questionnaire.

Participants who were followed up as adults were slightly less socioeconomically deprived than those not followed up but were no more likely to have been overweight or underweight in childhood. Birth weights were similar among the two groups.

During childhood, height progressively dropped away from contemporary norms, with a striking inverse social class gradient that narrowed in adulthood (table 1). In contrast, there was no social class gradient for body mass index in childhood, although there was a tendency for the children in the lowest social class to be thinner. Body mass index rose substantially through puberty and adulthood, and by the age of 50, $140(60 \%)$ men and $120(41 \%)$ women were overweight (body mass index $>24$ ), of whom 91 $(17 \%$ of both sexes) were obese (body mass index $>30)$. Those in the lower social classes at birth had significantly higher body mass index and percentage body fat at 50, whereas adult social class showed only a weak association with adult obesity.

\section{Relation between childhood and adult obesity}

Body mass index in childhood showed a moderate, significant correlation with adult body mass index (age 9:

Table 2 Proportions of children underweight or overweight at ages 9 or 13 years who were overweight or obese at age 50

\begin{tabular}{|c|c|c|c|c|c|c|}
\hline $\begin{array}{l}\text { Body mass } \\
\text { index } \\
\text { percentile } \\
\text { group }\end{array}$ & $\begin{array}{l}\text { No }(\%) \text { of } \\
\text { children } \\
\text { measured } \\
\text { at both } \\
\text { time points }\end{array}$ & $\begin{array}{c}\text { No (\%) } \\
\text { overweight } \\
\text { age } 50^{*}\end{array}$ & $\begin{array}{c}\text { No }(\%) \text { obese } \\
\text { age } 50 \dagger\end{array}$ & $\begin{array}{l}\text { P value } \\
\left(\chi^{2} \text { for }\right. \\
\text { trend })\end{array}$ & $\begin{array}{l}\text { No (\%) in } \\
\text { top quarter } \\
\text { of } \% \text { body } \\
\text { fat age } 50 \neq\end{array}$ & $\begin{array}{c}P \\
\text { ( } \chi^{2} \text { for } \\
\text { trend) }\end{array}$ \\
\hline \multicolumn{7}{|l|}{ Age 9: } \\
\hline$<25$ th & $99(23)$ & $37 / 99$ (37) & 8/99 (8) & \multirow{4}{*}{$<0.001$} & $17 / 73(23)$ & \multirow{4}{*}{0.23} \\
\hline 25-74th & $244(58)$ & $141 / 244(58)$ & 29/244 (12) & & $38 / 185(20)$ & \\
\hline 75-90th & 57 (13) & $25 / 57$ (44) & $16 / 57(28)$ & & $13 / 37$ (35) & \\
\hline$>90$ th & $24(6)$ & $8 / 24(33)$ & $10 / 24(42)$ & & $5 / 17(29)$ & \\
\hline \multicolumn{7}{|l|}{ Age 13: } \\
\hline$<25$ th & 119 (32) & $45 / 119$ (38) & $6 / 119(5)$ & \multirow{4}{*}{$<0.001$} & $23 / 93(24)$ & \multirow{4}{*}{0.014} \\
\hline 25-74th & 178 (47) & $96 / 178(54)$ & 25/178 (14) & & $22 / 128(17)$ & \\
\hline 75-90th & 40 (11) & $22 / 40(55)$ & $9 / 40(22)$ & & $8 / 30(27)$ & \\
\hline$>90$ th & $38(10)$ & 16/38 (42) & $17 / 38(45)$ & & $14 / 28(50)$ & \\
\hline
\end{tabular}

*Body mass index 24-30. †Body mass index $>30$. $¥$ Data on $\%$ body fat were available for fewer adults than data on body mass index 
Table 3 Association between risk factors age 50 with body mass index at ages 9,13 , and 50 years and percentage body fat (values are standardised regression coefficients)

\begin{tabular}{|c|c|c|c|c|c|c|c|c|}
\hline \multirow[b]{2}{*}{ Risk factor } & \multicolumn{4}{|c|}{ Women } & \multicolumn{4}{|c|}{ Men } \\
\hline & BMI age 9 & BMI age 13 & BMI age 50 & $\%$ fat age $\mathbf{5 0}$ & BMI age 9 & BMI age 13 & BMI age 50 & $\%$ fat age $\mathbf{5 0}$ \\
\hline Systolic blood pressure & -0.03 & 0.04 & $0.40^{* * *}$ & $0.30^{* * *}$ & -0.02 & 0.05 & $0.30^{* * *}$ & $0.29^{\star * *}$ \\
\hline Fibrinogen & -0.03 & -0.03 & $0.18^{\star \star}$ & $0.31^{* \star *}$ & -0.03 & 0.16 & 0.14 & $0.23^{\star \star}$ \\
\hline Total cholesterol & $-0.15^{*}$ & -0.13 & 0.05 & 0.12 & -0.05 & 0.02 & $0.21^{\star *}$ & $0.29^{* \star *}$ \\
\hline Triglyceride† & $-0.18^{*}$ & -0.06 & $0.29^{* \star \star}$ & $0.24^{\star * \star}$ & -0.10 & 0.04 & $0.36^{* \star *}$ & $0.40^{\star * *}$ \\
\hline 2 hour glucose $\dagger$ & -0.12 & -0.14 & $0.24^{\star \star \star *}$ & 0.10 & -0.13 & 0.03 & $0.33^{* * *}$ & $0.25^{\star \star}$ \\
\hline Serum insulin† & -0.05 & 0.01 & $0.58^{* * *}$ & $0.46^{* * *}$ & -0.08 & -0.04 & $0.44^{* * *}$ & $0.44^{* \star *}$ \\
\hline
\end{tabular}

$r=0.24, \mathrm{P}<0.001$; age 13: $r=0.39, \mathrm{P}<0.001)$. At age 50 , those who had been above the 90 th centile for body mass index at age 9 or 13 years were between five and nine times more likely to be obese (body mass index $>30$ ) than those in the thinnest quarter in childhood (table 2). The association between body mass index in childhood and adult percentage body fat was weaker than that with adult body mass index (age 9: $r=0.1$, $\mathrm{P}=0.07$; age 13: $r=0.22, \mathrm{P}<0.001$ ). Little tracking was seen between any level of body mass index at age 9 and adult percentage body fat. Children in the top tenth of

Table 4 Association between body mass index at ages 9 and 13 years in childhood and risk factors age 50 , adjusted for body mass index age 50 (values are standardised regression coefficients)

\begin{tabular}{|c|c|c|c|c|}
\hline \multirow[b]{2}{*}{ Risk factor age 50} & \multicolumn{2}{|c|}{ Women } & \multicolumn{2}{|c|}{ Men } \\
\hline & BMI age 9 & BMI age 13 & BMI age 9 & BMI age 13 \\
\hline Carotid thickness & -0.02 & 0.10 & -0.11 & -0.07 \\
\hline Systolic blood pressure & $-0.15^{\star}$ & -0.10 & -0.09 & 0.01 \\
\hline Diastolic blood pressure & $-0.16^{*}$ & -0.06 & -0.11 & -0.11 \\
\hline Fibrinogen & -0.07 & -0.08 & -0.05 & 0.13 \\
\hline Total cholesterol & $-0.17^{*}$ & -0.16 & -0.11 & -0.12 \\
\hline HDL cholesterol† & -0.04 & -0.04 & 0.07 & 0.05 \\
\hline LDL cholesterol† & -0.15 & -0.03 & -0.13 & 0.01 \\
\hline Triglyceride† & $-0.27^{* *}$ & $-0.19^{\star}$ & $-0.18^{\star}$ & -0.12 \\
\hline 2 hour glucose $\dagger$ & $-0.17^{*}$ & $-0.20^{\star}$ & $-0.22^{\star *}$ & -0.03 \\
\hline Serum insulin† & $-0.20^{* *}$ & $-0.21^{\text {** }}$ & $-0.17^{\star}$ & $-0.23^{* \star}$ \\
\hline
\end{tabular}

${ }^{*} \mathrm{P}<0.05,{ }^{* *} \mathrm{P}<0.01,{ }^{* * *} \mathrm{P}<0.001$

$\dagger$ Logged values.

$\mathrm{BMI}=$ body mass index, LDL=low density lipoprotein, $\mathrm{HDL}=$ high density lipoprotein

Table 5 Association between body mass index at age 9 and 13 years and risk factors at age 50 , adjusted for percentage body fat age 50 (values are standardised regression coefficients)

\begin{tabular}{|c|c|c|c|c|}
\hline \multirow[b]{2}{*}{ Risk factor age $\mathbf{5 0}$} & \multicolumn{2}{|c|}{ Women } & \multicolumn{2}{|c|}{ Men } \\
\hline & BMI age 9 & BMI age 13 & BMI age 9 & BMI age 13 \\
\hline Carotid thickness & 0.01 & 0.11 & -0.04 & -0.07 \\
\hline Systolic blood pressure & -0.08 & -0.01 & 0.01 & 0.04 \\
\hline Diastolic blood pressure & -0.08 & -0.04 & 0.01 & -0.06 \\
\hline Fibrinogen & -0.08 & -0.11 & 0.004 & 0.13 \\
\hline Total cholesterol & $-0.17^{\star}$ & -0.16 & -0.02 & -0.02 \\
\hline HDL cholesterol† & -0.08 & -0.11 & -0.01 & -0.09 \\
\hline LDL cholesterol† & -0.14 & -0.13 & -0.03 & -0.06 \\
\hline Triglyceride† & $-0.21^{\star *}$ & -0.12 & -0.06 & -0.001 \\
\hline 2 hour glucose $\dagger$ & -0.14 & -0.16 & -0.12 & 0.01 \\
\hline Serum insulin† & -0.12 & -0.08 & -0.03 & -0.08 \\
\hline
\end{tabular}

body mass index at age 13 were twice as likely as the remainder to be in the top quarter for adult percentage body fat, but children in the bottom quarter were equally likely to have either high or low body fat as adults. Most of those in the top quarter for body fat aged 50 had not been overweight as children: $94 \%$ had been below the 90 th percentile for body mass index at age 9 and $79 \%$ at age 13 .

Although adult percentage body fat was strongly correlated with adult body mass index $(r=0.63, \mathrm{P}$ $<0.01$ ), for every level of adult body mass index the leanest children had significantly higher adult percentage body fat (linear regression: body fat $(\%)=5.4 \times$ body mass index aged $50-1.1 \times$ body mass index aged $9+32.5$ ).

\section{Relation between childhood obesity and adult risk factors}

In univariate analysis, body mass index and percentage body fat aged 50 were both strongly associated with most risk factors for adult disease (table 3). Body mass index at age 9 and 13 showed weak (mainly inverse associations with risk factors, although the only significant associations were between body mass index age 9 and total cholesterol and triglyceride concentrations in women. After adult body mass index was adjusted for, childhood body mass index showed consistent inverse associations with risk of adult disease. In women, associations with body mass index age 9 were significant for triglycerides, fasting insulin, 2 hour glucose, systolic and diastolic blood pressure, and total cholesterol, and associations with body mass index at age 13 were significant for triglyceride, fasting insulin, and 2 hour glucose concentrations. In men, there were significant associations between body mass index at age 9 and triglyceride, fasting insulin, and 2 hour glucose concentrations and between body mass index at age 13 and fasting insulin concentration (table 4).

When we adjusted for adult percentage body fat rather than body mass index, the striking relations between childhood body mass index and fasting insulin and 2 hour glucose concentrations were much attenuated in women and largely disappeared in men (table 5). Similarly, the association between childhood body mass index and adult blood pressure largely disappeared.

For women, the association between body mass index aged 9 and cholesterol and triglyceride concen- 
trations remained significant, with those women thinnest at age 9 having higher concentrations for every stratum of adult fatness. The non-significant correlations between childhood body mass index and adult risk factors were still consistently inverse for both sexes and ages. Including social class at birth, height, or weight in childhood made little difference to these results.

The 47 subjects who had died in adulthood and the 20 subjects who met the full criteria for the metabolic syndrome were no more likely to have been in the top quartile for body mass index at ages 9 or 13 years than the others.

\section{Discussion}

We found that although overweight teenagers were more likely to become fat adults, most fat adults were not overweight as children and those thin in childhood and adolescence were not protected from obesity as adults. The absence of an association between body mass index at age 9 and percentage body fat at age 50 suggests that the association between childhood and adult body mass index, seen in this and previous studies, may mainly reflect tracking of build rather than fatness. Muscle mass and the size of the bony frame also contribute to body mass index. This is particularly relevant in children, in whom obesity is rare and lean mass makes a substantial contribution to body mass index. ${ }^{18}$ This may explain why raised childhood and teenage body mass index showed no positive association with risk of adult disease. In fact, the trend was consistently negative, suggesting that those thinnest in childhood have the highest overall risk of adult disease.

\section{Strengths and weaknesses}

The main strength of this study is that we could link prospectively collected early anthropometric and social data to a wide range of measures collected in adulthood. These included an estimate of body fat that is largely independent of build. Although biolectrical impedance is not widely used clinically, it has high validity and is reliable when used by trained operators in people of average build. ${ }^{19}$ Its validity is shown in this study by the strong correlations found with both adult body mass index and risk factors for disease.

One weakness is that we had data on a relatively small number of participants at both periods and follow up was only to age 50 . This meant that we could use only well validated proxy markers for morbidity rather than actual outcomes.

An inevitable limitation of any long term follow up study from childhood is that its subjects will have grown up in different circumstances. It could thus be argued that our findings cannot be generalised to today's children. The subjects were a postwar cohort, protected by the same welfare safety net as today, and parental unemployment rates were low. Compared with modern childhood norms, participants were short but had similar body mass index values with close to the expected proportion of both overweight and underweight children. Our data should be treated with the same caution as those of any other long term follow up study while recognising that they provide vital information that is unlikely to be gleaned by any other method.

\section{Other studies}

Data on overweight from long term studies are rare. Three studies in teenagers and young adults found a pattern of associations between current overweight and disease risk factors similar to that expected in later adulthood, but these children were not followed into later life. ${ }^{10} 20{ }^{21}$ Only two other comparable studies have examined later adult risk in relation to both childhood and adult overweight, ${ }^{172}$ and these used body mass index as a measure of obesity at both ages. Vanhala et al found that fat children who went on to be fat adults had a threefold increased risk of developing the metabolic syndrome compared with those who became fat as adults. ${ }^{17}$ However, using the same definition of the metabolic syndrome, we were not able to find any association in our similar data set.

Another large early study that measured a similar range of risk factors to ours, also found no overall excess adult disease risk from high childhood body mass index and that men thinnest in childhood were at greatest risk after adjustment for adult body mass index..$^{22}$ The authors speculated that this might simply be an artefact of the use of body mass index at both time points, suggesting that those relatively thin in childhood would tend as adults to have a higher percentage body fat per unit of body mass index. We were able to test and confirm this hypothesis. In men in our study, the inverse relation of childhood body mass index with blood pressure and serum insulin concentration at age 50 was not seen when percentage body fat was used to adjust for adult fatness rather than body mass index. This suggests that some of the inverse relations were a result of residual confounding by adult fatness, because body mass index had incompletely adjusted for adult fatness. However, the effects in women on lipid and glucose metabolism were largely unchanged, suggesting that they were true effects.

The absence of an association between childhood overweight and adult risk must be placed within the context of other studies. Perhaps the most important evidence is found in mortality studies. Five studies have examined male all cause mortality, ${ }^{4-8}$ and one cardiovascular mortality, ${ }^{9}$ after early overweight. Weight was mostly measured in the late teens, and men were followed up to middle age. All found a trend towards increased mortality among those who were fattest in their childhood or teens, and a similar but weaker trend has been found in women. ${ }^{568}$ However, the two largest and thus most robust studies suggest that the increased risk is found only in the fattest $1-2 \%$, (relative risk of 2) with no trend to excess death with lesser overweight. ${ }^{4}$ Both studies also found a trend to higher mortality in the thinnest $1-5 \%$ (relative risk 1.5), and the excess deaths attributable to either overweight or underweight in these studies each represented only $1-2 \%$ of all premature deaths. Thus premature death rates do seem to be raised in adults who were most overweight as children, but the absolute number of deaths is small, and the strongest evidence is for those obese late in adolescence rather than childhood.

\section{Implications for life course epidemiology}

Our findings also have relevance to the exploration of life course influences on adult health. Weight and thin- 


\section{What is already known on this topic}

Many studies have found that body mass index in childhood is significantly correlated with body mass index in adulthood

Obese children have been found to have higher all cause mortality as adults

\section{What this study adds}

No excess health risk from childhood overweight was found

Childhood body mass index was linked to adulthood body mass index but not percentage body fat

Only children who were obese at 13 showed a significant increased risk of obesity as adults

People who were thinnest as children and fattest as adults tended to have the highest adult risk

ness at birth have been found to be inversely related to a range of adult health outcomes. However, it is probably a change in relative size from birth to adulthood rather than small size itself that predisposes to later morbidity. ${ }^{23}$ This theory has been interpreted in terms of the intrauterine environment compared with postnatal growth, but a similar inverse relation has been shown between weight at age 1 year and glucose tolerance in 59-70 year old men after adjustment for adult body mass index. ${ }^{24}$ Our study shows a similar effect taking place after childhood, which suggests that it is not restricted to one critical phase of development in the perinatal period.

These data also have methodological implications for the use of growth data in longitudinal studies. Previous studies have found inverse association between thinness at birth and adult morbidity after adjusting for adult fatness by using body mass index. ${ }^{25}{ }^{26}$ Our data suggest that these apparent relations could simply be artefact, with risks inadvertently ascribed to thinness at birth in fact resulting from adult fatness having been underestimated.

\section{Conclusions}

There is a widespread popular belief that adult fatness begins in childhood, despite evidence from many studies that most fat adults were not fat children. Current concerns about rising rates of overweight in children also hinge on the assumption that fat children are more likely to become fat adults. Our data suggest a much less deterministic situation. There was a high degree of variation between childhood and midlife in degrees of fatness and no net increase in adult disease risk for overweight children or teenagers, despite children who were overweight at 13 being twice as likely to go on to be obese adults. This is probably because half of those overweight at 13 did not become obese adults, while those thinnest in childhood who went on to be fat adults experienced the most adverse consequences.

Our data suggest that whole population interventions in childhood directed at reducing body mass index in childhood may not benefit adult health. Meanwhile, underweight in childhood should still be a focus of concern since it offers no protection against adult obesity and is associated with increased risk of adult disease.

We thank Professor George Alberti for his help in designing and directing the study; Janice Gebbie, Jean Gerrard and Mavis Brown, the study nursing staff; and Melanie Cohen and Julian Smith for retrieving and collating early growth data.

Contributors: LP and AWC initiated and designed the study and provided overall supervision. DL coordinated the study and was responsible for data processing and initial analyses. CMW performed the main analysis, drafted the paper, and coordinated subsequent revisions with the other authors. CMW is the guarantor.

Funding: Wellcome Trust, James Knott Trust, Northern Regional Health Authority.

Competing interests: CMW has a longstanding interest in undernutrition in childhood.

1 Chinn S, Rona RR Prevalence and trends in overweight and obesity in three cross-sectional studies of British children 1974-94. BMJ 2001:322:24-6.

2 Power C, Lake JK, Cole TJ. Measurement and long term health risks of child and adolescent fatness. Int J Obesity 1997;21:507-26

3 Hoffmans MDAF, Kromhout D, de Lezenne Coulander C. Body mass index at the age of 18 and its effects on 32 year mortality from coronary heart disease and cancer: a nested case-control study among the entire 1932 Dutch male birth cohort. J Clin Epidemiol 1989;42:513-20.

4 Hoffmans MDAF, Kromhout D, de Lezenne Coulander C. The impact of body mass index of 78,612 18-year old Dutch men on 32 year mortality from all causes.J Clin Epidemiol 1988;41:749-56.

5 Must A, Jacques PF, Dallal GE, Bajema CJ, Dietz WH. Long-term morbidity and mortality of overweight adolescents: a follow-up of the Harvard growth study of 1922 to 1935 . N Engl J Med 1992;327:1350-5.

6 Nieto FJ, Szklo M, Comstock GW. Childhood weight and growth rate as predictors of adult mortality. Am J Epidemiol 1992;136:201-13.

7 Allebeck P, Bergh C. Height, body mass index and mortality: do social factors explain the association. Public Health 1992;106:375-82.

8 Gunnell DJ, Frankel SJ, Nanchahal K, Peters TJ, Davey Smith G. Childhood obesity and adult cardiovascular mortality: a 57 -year follow-up study based on the Boyd Orr cohort. Am J Clin Nutr 1998;67:1111-8.

9 Eriksson JG, Forsen T, Tuomilehto J, Winter PD, Osmond C, Barker DJP Catch-up growth in childhood and death from coronary heart disease: longitudinal study. BMJ 1999;318:427-31.

10 Srinivasan S, Bao W, Wattigney WA, Berenson GS. Adolescent overweight is associated with adult overweight and related multiple cardiovascular risk factors: the Bogalusa heart study. Metabolism 1996;45:235-40.

11 Spence J, Walton WS, Miller FJW, Court SDM. A thousand families in Newcastle upon Tyne. London: Oxford University Press, 1954.

12 Lamont D, Parker L, Cohen M, White M, Bennett S, Unwin N, et al. Early life and later determinants of adult disease: a 50-year follow-up study of the Newcastle thousand families cohort. Public Health 1998;112:85-93.

13 Lamont D, Parker L, White M, Unwin N, Bennett S, Cohen M, et al. Risk of cardiovascular disease measured by carotid intima-media thickness at age 49-51: lifecourse study. BMJ 2000;320:273-8.

14 Tanner J, Whitehouse R, Takaishi M. Standards from birth to maturity for height weight height velocity and weight velocity: British children 1965 . Part I. Arch Dis Child 1966;41:454-71.

15 Cole TJ. The LMS method for constructing normalized growth standards. Eur J Clin Nutr 1990;44:45-60.

16 Cole TJ, Freeman JV, Preece MA. Body mass index reference curves for the UK, 1990. Arch Dis Child 1995;73:25-9.

17 Vanhala M, Vanhala P, Kumpusalo E, Halonen P, Takala J. Relation between obesity from childhood to adulthood and the metabolic syndrome: population based study. BMJ 1998;317:319.

18 Fomon SJ, Haschke F, Ziegler EE, Nelson SE. Body composition of reference children from birth to age 10 years. Am J Clin Nutr 1982;35:1169-75.

19 Garrow JS. Composition of the body. In: Garrow JS, James WPT, Ralph A, eds. Human nutrition and dietetics. 10th ed. Edinburgh: Churchill Livingstone, 2000:13-22.

20 Freedman DJ, Dietz WH, Srinivasan SR, Berenson GS. The relation of overweight to cardiovascular risk factors among children and adolescents: the Bogalusa heart study. Pediatrics 1999;103:1175-81.

21 Lauer RM, Lee J, Clarke WR. Factors affecting the relationship between childhood and adult cholesterol levels: the muscatine study. Pediatrics 1988;82:309-18

22 Abraham S, Collins G, Nordsieck M. Relationship of childhood weight status to morbidity in adults. HSMHA Health Report 1971;86:273-84.

23 Lucas A, Fewtrell MS, Cole TJ. Fetal origins of adult disease-the hypothesis revisited. $B M J$ 1999;319:245-9.

24 Hales CN, Barker DJP, Clark PM, Cox LJ, Fall C, Osmond C, et al. Fetal and infant growth and impaired glucose tolerance at age 64. BMJ 1991:303:1019-29.

25 Lithell HG, McKeigue PM, Berglund L, Mohsen R, Lithell U-B, Leon DA. Relation of size at birth to non-insulin dependent diabetes and insulin concentrations in men aged 50-60 years. BMJ 1996;312:406-10.

26 Phillips DW, Barker DJP, Hales CN, Hirst S, Osmond C. Thinness at birth and insulin resistance in adult life. Diabetologia 1994;37:150-4.

(Accepted 29 August 2001) 